\title{
Study on Perception of Organization Justice among Non-Academic Staff of Tertiary Education in Selangor Malaysia
}

\author{
Agbonmwandolor Bobby Efosa ${ }^{1} \&$ Amirreza Salehipour $^{1}$ \\ ${ }^{1}$ Department of Project Management, Postgraduate Studies Centre, Limkokwing University of Creative \\ Technology, Malaysia \\ Correspondence: Agbonmwandolor Bobby Efosa, Department of Project Management, Postgraduate Studies \\ Centre, Limkokwing University of Creative Technology, Malaysia. E-mail: secman_3012@yahoo.com
}

Received: June 8, 2018

Accepted: July 18, 2018

Online Published: August 1, 2018

doi:10.5539/ijbm.v13n9p67

URL: https://doi.org/10.5539/ijbm.v13n9p67

\begin{abstract}
High turnover intention rate would negatively affect organizations productivity and overall performance, also hiring and training new employees might result in extra expenses. Therefore, authors of this study focused on Organizational Justice as one of the main reasons for turnover intention from the three dimensions.

Based on the following adopted variables: procedural justice, interactional justice and distributive justice; Distinctive study conducted by distributing questionnaire to 140 non-academic members of tertiary education institutes to investigate and obtain appropriate answers for the given research questions of this probe.

The findings of hypotheses testing demonstrate that Organizational Justice has significantly effects on non-academic members of tertiary education's turnover intention rate and illustrate strong relation between variables. Outcome of current research indicate that tertiary education institutes in Malaysia require immediate adequate action toward improving organizational justice to develop productivity and performance of their non-academicals employees and diminish turnover intention rate.
\end{abstract}

Keywords: organizational justice, employee turnover intentions, procedural justice, interactional justice and distributive justice.

\section{Introduction}

\subsection{Problem Statement}

Several researchers including, Guo (2009), Iyer (2011), Moris and Leing (as cited in Fodchuk 2009), Pyun (1997), Oh (2013) and Zhang (2006) have stated previously that in non-Western countries like Malaysia, the study of Organizational Justice is not as abundant and frequent. They also proclaimed that the models and schemes applied in the Western culture may not provide the same results in a different culture. At the same time, there were research including, Choong Wong and Tioh (2010), Tam (1998), and Wan Sulaiman \& Omar (2012) who focused and researched on OJ discrete to the Malaysian culture but their main focus was on other areas. Organizational Justice is understood as an individual's understanding of equity and fairness in an institution or organization (Greenberg 2010) and it is the essential basis in apprehending the way that employees feel or think about their organization (Miller et.al. 2012 as cited by Gauri 2013). The findings of Pekurinen et al. (2017) lights that organizational justice, cooperation amongst employees, and violent attacks by patients have linkage with hospital settings for psychiatry. Considering different elements such as organizational justice related issues and cooperation between nurses might help to reduce assaults. In conclusion, the equity understood by an individual can be extensively classified into the following 4 categories:

\subsubsection{Distributive Justice}

If we refer to Al Rawashdeh (2013), we can understand that this category refers to the profit or benefit of an individual gained due to his/her commitment toward the specific task done by him/her in the organization. Another fact that is also emphasized on by Gauri (2013) is that, the understanding of equity is based on an individual's achievements being compared with someone else's achievements that had the same responsibility in the same institution. 


\subsubsection{Procedural Justice}

Al Rawashdeh (2013) expressed, was that the approach and methodology used to regulate the outcome of an employee's contribution is classified under this category. As an allusion to Belanger (2007), Procedural Justice is particularly observing the equity and fairness of conventional decision-making schemes hired by an institution to estimate the result an employee's contribution.

\subsubsection{Interpersonal Justice}

The early decade was also known as the Interpersonal (Interactional) Justice. This category is more about how a supervisor or an authority approaches the employees in an organization, and whether these employees are being treated with dignity and honor (Iyer 2011; McNabb 2009). Likewise, Interpersonal Justice has been described as an equitable behaviour towards an employee by other workers in an institution by Belanger (2007). Positive Organizational Justice would have advantages for an institution along with numerous beneficial institutional results. One of these benefits is elevated employee turnover intentions (Georgalis, J. et al. 2015).

All in all, the principal issue is to look into and simplify the studies on whether Organizational Justice has a positive or negative effect on non-academic employees' Turnover Intentions in tertiary industries specifically in Malaysia. As a result, numerous procedures will be executed to analyses the issue.

Fodchuk 2009) emphasized on the fact that inaccuracies such as wrong interpretations of meanings, culture prejudice and elimination of certain cultural behaviors will be made due to the translation of measurements of psychological theories to other cultures. If we take everything that was discussed earlier into account, we can understand that there are limitations in non-Western countries when it comes to empirical Organization Justice studies (Fodchuk 2009; Guo 2009; Pyun 1997; Zhang 2006).

The reduction of $10 \%$ turnover in a medium sized institution with roughly 1000 employees is approximately $\$ 7.5$ million in accordance with what Bliss has said (Hamlett, 2014). Those losses include apprehension, revenue, practical skills and knowledge, and positions that will be unoccupied since an employee leaves it behind due to his withdrawal. Therefore, both institutions and employees will be favored and have benefits if the Organizational Justice maintained. If there are any disappointments and unhappiness towards anything, the company is responsible to manage and reduce the negative impact in a short time. Finally, employees and respondents who read this research can create consciousness towards the idea and model of OJ in their companies.

\subsection{Research Objectives}

The purpose of this study can be divided into 2 categories which includes, The General Objectives and The Specific Objectives as mentioned below:

\subsubsection{General Objectives}

To expose and gain genuine insight about how employee in Malaysia perceives and judges fairness in their organization. The overall aim of this study is to detect and analyses whether the Turnover Intention of non-academic employees in Malaysian companies is influenced by Distributive Justice, Procedural Justice, and Interpersonal Justice or not.

\subsubsection{Specific Objectives}

The objectives mentioned below are intended to be achieved in accordance with The General Objectives.

Objective 1: To deduce whether or not an employee understands towards Turnover Intentions is positively influenced by Distributive Justice.

Objective 2: To deduce whether or not an employee understands towards Turnover Intentions is positively influenced by Procedural Justice.

Objective 3: To deduce whether or not an employee understands towards Turnover Intentions is positively influenced by Interpersonal Justice.

\section{Literature Review}

The social science terminology "Organizational Justice" was first coined by Greenberg in 1990 (Hamlett 2014; Zhang 2006). Each of the words used in the term have their separate meanings which will make it easier for people or employees to understand the terminology. A working environment in the society is referred to as an "Organization" and when we mention the term "Justice" we are actually referring to the equity assigned in that working environment. In 1971, a philosopher named John Rawls mentioned that equity is the synonym of "Justice" and Robinson (2004) cited from this philosopher later on. He also pinpointed that in any institution or 
company the very first important thing that needs to be carried out is justice and fairness towards its employees. In addition, John described details regarding rational recognition of equity principles and instructions. When it came to Justice, there were 2 significant rules that John always took action according to those. The first rule mentioned that it was the right of each and every individual to enjoy basic civil rights and freedoms and the second rule mentioned that, each individual is supposed to have the coequal rights and options in the society. It was mentioned by John that in those times, there were unfair issuance of resources because only those people who had talents and interests had the chance to excel. Later on, Cohen and Greenberg (cited in Robinson 2004) were among the first researchers who found a correlation between the field psychology and the philosophical literature regarding Justice.

\subsection{Turnover Intention}

If we refer to Tett and Meyer (1993) we can understand that they described Turnover Intention as the intentional and readiness of personnel to abandon their institution. Technically, this is the final in the progression of Withdrawal Cognition, which includes, considering leaving and applies to look for a replacement job. Even though, TIs do not always cause actual turnover, however Bluedorn (1982) discovered that Turnover Intentions had a high relation with actual turnover in the past 13 or 14 data collected researches. Actually, researches carried out based on Turnover Intentions, show that Turnover Intentions is the most regular factor for elective turnover (Lambert, Hogan, \& Barton, 2001).

\subsection{Organizational Justice and Employer Turnover Intention}

Refer to Moorman (1991), once working staff have started to understand their institution, they start to show positive behavior and good working morale towards their given tasks, results, and their superiors. Most researchers have a classic analogy on Turnover Intention (Hellman, 1997); as a result, Turnover Intention normally refers to an employee's will to leave a company, or the removal of an employee by a superior for the good of the company. Researches based on data collection demonstrate that Turnover Intentions the most influential factors that predict the actual Turnover attitude (Griffeth, Hom and Geatner, 2000; Hemdi, 2006). In reality, there is actually an important correlation between TI and the actual Turnover (Lambert, Hogan and Barton, 2001).

\subsection{Job Satisfaction}

The idea of inspiration in correlation with work fulfillment is specified in past studies, according to Hamlett (2014), work fulfillment is made by "Motivators" factor. Same with the Value Theory of occupation fulfillment (Greenberg 2010), "Motivators" is an ambiguous word used in the work fulfillment setting. It can include numerous positive results or factors that a worker values, for example, individual or group accomplishments, productive diligent work, receiving rewards, acknowledgment or affirmation from others, included duty, profession development, individual improvement and so on.

\subsection{Organization Justice and Job Satisfaction}

The concept of "Employee First, Customer Second" (EFCS) is coined by the American CEO of HCL Technologies, Vineet Nayar (2010) who steers one of the largest I.T. outsourcing firms in the world. His idea is to value and treat employee with respect and full support, then this respect and good will would be pass to the customer, eventually benefit the company. While in Malaysia, with reference to British Broadcasting Corporation (BBC) (2010), Group CEO of Air Asia, Malaysian home grown low-cost air Flight Company, Tony Fernandez also adapted the same philosophy in managing the 8000 work forces of Air Asia (as of 2010).

\subsection{The Impact of Misconceptions and Prejudices on Employees' Understanding of Equity}

The study of the organizational decisions in the legal area shows that organizational performance evaluation that have been open to be examined by legal authorities also encourage the popularity of organizational justice; some scientists who have examined the matter, even believe that points concerning equity and its practice are considered more significant when making decisions in the legal system about appraisal of organizational performance than the rather scientific matter of choosing a valid sort of measuring device for evaluation (Barrett and Kernan, 1987; Werner and Bolino, 1997). Based on some studies, there is a connection between the idea of how fair the appraisal of performance in and organization is and other aspects of fairness in the same place e.g. existence of opportunities to have a say in the proceedings of organizational evaluation (Barrett and Kernan, .1987; Werner and Bolino, 1997).

\subsection{Distributive, Interactional, and Procedural Justice,}

There seems to interrelations among the three classes of fairness introduced in the previous paragraph; however, 
the collective analyses of the data from several separate studies on the matter show unique incremental variance explaining the exact difference between them(Cohen and Spector, 2001; Colquitt, et al, 2001; Hauenstein, 2001). Based on the definition, interactional fairness is how well the employees are treated when courses of action are taking place, (Bies and Moag, 1986). There are four characteristics to show the distinctive line between this type of fairness and the others: respect i.e. how considerate the management behaves towards the employees; truthfulness, if the employer hides any truth from the employees; justification, provision of information and clarification on the current courses of action in the organization; and propriety, how unprejudiced the employer is, (Greenberg, 1993; Moorman, 1991).

\section{Methodology}

\subsection{Research Framework}

There are three independent variables on the left i.e. distributive justice, DJ, procedural justice, PJ, and interpersonal justice, IJ which may be in positive correlation with the dependent variable of the study i.e. the turnover intention of the employee, ETI. Multiple linear regressions have been devised to determine the relationship between the two sets of variables.

The model provides a tabular representation of the study subject, its objectives as well as the questions to be provided with an answer. It has been prepared on the basis of and adapted from past studies, Russell et al. (2006), Bowen et al. (1999), Oh (2013), and Vineet (2010) which contained findings suggesting that Organization Justice is positively correlated to ETI, motivation as well as working quality.

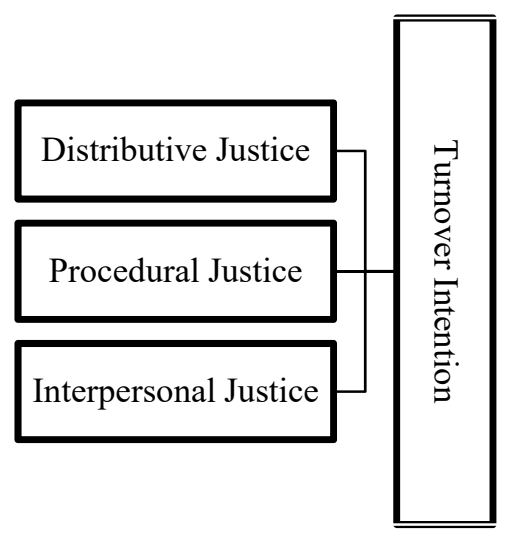

\subsection{Hypotheses of the Study}

By referring to the research questions designed in the previous section, we can come up with several hypotheses which are listed below to analyses the correlation between the independent variables and the dependent variable.

H1. There is positive correlation between employee's Turnover Intentions and Distributive Justice.

H2. There is positive correlation between employee's Turnover Intentions and Procedural Justice.

H3. There is positive correlation between employee's Turnover Intentions and Interpersonal Justice

\subsection{Research Instrument}

In order to gather primary analysis for this study, a survey would be handed out to employees who work in Malaysian tertiary education institutions. In order to demonstrate the instrument, variable amount of OJ was measured using a 25 -items scale made by Niehoff \& Moorman (1993). The Justice scale has 3 dimension measurements of understanding Distributive Justice with five items, Procedural Justice with six items, and Interactional Justice with nine items. Turnover Intention which is the basic value was measured with a five item scale adapted from Hom \& Griffeth (1995).

\subsection{Research Design}

Refer to Burns \& Bush (2006 p.116), we can understand that "Research Design" refers to a layout of a model of in advanced decisions in the techniques to gather and examine information. It is similar to a master design in constructing a building where several factors like the width, height, instruments and etc. of the building is firstly determined and then the actual construction starts. Both quantitative and qualitative studies will be carried out to 
analyses the correlation between the three independent variables and the dependent variable, which is the Turnover Intention, as the objective of this research. In this situation, a quantitative study refers to the questionnaire features regarding numbers while the qualitative study refers to the questionnaire features having no numbers and statistical measurements. These questionnaires are distributed among Malaysian institutions and the responses regarding realization of equity would be collected.

\subsubsection{Target Population}

Malaysian non-academic staff employees in tertiary institution in Selangor, despite their gender, age, ethnicity and amount of monthly salary who can be reached out to by electronic mail or in face-to-face have been selected as the possible respondents to the research. 2 types of surveys where distributed among the respondents which were online and printed questionnaires. All of the Malaysian companies' working staffs who came into correspondence when the data collection (either by email or face-to-face) was going on, responded to the questionnaires on a voluntary basis due to the nature of Convenience Sampling Method.

\section{Result and Discussion}

\subsection{Descriptive Analysis}

Descriptive statistics describes the information obtained from a study and provides summaries of the sample and measures utilized. It starts with the analyses of the respondents' personal data bothering on gender, age, Religion, Education level, Marital Status, Monthly Income, Ethnicity, Area of your academic qualification, How long have you worked for this Institution and what is your management levels. The explanations provided in this chapter are gathered from the information received from an analytical method called, Statistical Package for Social Sciences (SPSS, for short).

\begin{tabular}{|c|c|c|c|}
\hline Category & Items & No. Of Respondents & Percentage \\
\hline \multirow[t]{2}{*}{ Gender } & Male & 76 & 54.3 \\
\hline & Female & 64 & 45.7 \\
\hline \multirow[t]{4}{*}{ Age } & $18-25$ & 86 & 61.4 \\
\hline & $26-35$ & 46 & 32.9 \\
\hline & $36-51$ & 6 & 4.3 \\
\hline & $52-70$ & 2 & 1.4 \\
\hline \multirow[t]{4}{*}{ Nationality } & Malay & 14 & 10.0 \\
\hline & Chinese & 10 & 7.1 \\
\hline & Indian & 44 & 31.4 \\
\hline & Others & 72 & 51.4 \\
\hline \multirow[t]{5}{*}{ Designation } & Business and Management & 78 & 55.7 \\
\hline & Science Technology & 12 & 8.6 \\
\hline & Engineering & 16 & 11.4 \\
\hline & Social Science & 10 & 7.1 \\
\hline & Others & 24 & 17.1 \\
\hline \multirow[t]{4}{*}{ Position } & Executive & 77 & 55.0 \\
\hline & Manager/Assistant & 28 & 20.0 \\
\hline & Senior/Deputy Senior Manager & 9 & 6.4 \\
\hline & Other & 26 & 18.6 \\
\hline \multirow[t]{4}{*}{ Educational Qualification } & Diploma & 22 & 15.7 \\
\hline & Bachelor & 46 & 32.9 \\
\hline & Master & 53 & 37.9 \\
\hline & $\mathrm{PhD}$ & 19 & 13.6 \\
\hline \multirow[t]{4}{*}{ Salary } & Less than Rm5, 000 & 107 & 76.4 \\
\hline & Rm5, 001-Rm 10,000 & 22 & 15.7 \\
\hline & Rm10, 001- Rm15, 000 & 5 & 3.6 \\
\hline & $\mathrm{Rm} 15,001-\mathrm{Rm}$ 20,000 & 6 & 4.3 \\
\hline \multirow[t]{3}{*}{ Work Experience } & $1-5$ years & 90 & 64.3 \\
\hline & $6-10$ years & 18 & 12.9 \\
\hline & More than 11 years & 32 & 22.9 \\
\hline \multirow[t]{5}{*}{ Relegion } & Islam & 81 & 57.9 \\
\hline & Buddhism & 14 & 10.0 \\
\hline & Christianity & 12 & 8.6 \\
\hline & Hinduism & 22 & 15.7 \\
\hline & Other & 11 & 7.9 \\
\hline Total & & 140 & 100.0 \\
\hline
\end{tabular}


The participants during this survey were composed of 76 males and 64 females with a complete proportion of $54.3 \%$ for men and $45.7 \%$ women. This means that the questionnaire was fairy distributed between each gender and therefore the percent tested was enough to work out their characteristics. Respondents within the survey fell at intervals the age varies from 18 years to 71 years and above years. While majority of participants in the study are interval ages varying from 18 to 25 years. Also religion platform indicates most of the employees are Moslem (58\%) followed by Hinduism (16\%), Buddhism (10\%) and Christianity (8.6\%). Majority of respondents possessed master's degree (37.9\%); followed by bachelor degree holders $(32.9 \%)$, while diploma degree $(15.7 \%)$ and $\mathrm{PhD}$ degree $(13.6 \%)$ had the lowest variety of respondents. The greater part of respondents within the survey fell at the monthly income ranges of less than Rm5, 000 (76.4\%), which followed by Rm5, 001- Rm10, 000 $(15.7 \%)$ and just small number of employees receive $\mathrm{Rm} 10.001$ and above $(8 \%)$.

With reference to demographic table of our respondents more than half were foreigners (51.4\%), while Malay, Indian and Chinese (48.6\%) considered local. According to the survey on area of your academic qualification, highest number of respondents which are 78 respondents $(55.7 \%)$ doing business and management. Then engineering department is the third highest that represented by 16 respondents $(\mathbf{1 1 . 4 \% )}$. While science technology department is the fourth highest that represented by 12 respondents $(8.6 \%)$ and social science department is least which represent 10 respondents $(7.1 \%)$. Work experience referring to the amount of contribution employees has done to the company. The table indicates large number of respondents $(64.3 \%)$ have less than five years' experience, while some of members $(22.9 \%)$ have worked over 10 years in that company and the smallest group (12.9\%) belongs to those who have worked either from 5 to 9 years for the company. Also $55.0 \%$ are holding executive positing in their companies which followed by Manager/Assistant level with 20 percent and the lowest was senior/deputy senior manager position with $6.4 \%$.

\subsection{Overall Relationship for Pair of Variables}

\subsubsection{Scatter Diagram}

Figure 4.1, illustrating the general connection between each match of independent and dependent variable, it is recognizable that distributive justice and contentment with one's position in an organization, distributive justice shows a general growing pattern that implies the relation is in all likelihood positive which means; when distributive justice expanded, the Turnover Intention expanded likewise. Or, if Turnover Intention diminishes when distributive justice expands, it shows the relationship of the match of variables is not positive. The same increasing pattern is observed for Procedural justice, Interpersonal Justice. In this way, it can be justifiably forecast the Turnover Intention of a respondent according to the measurements of the three dependent variables of that specific respondent. Yet, the real relation and its quality are separately considered in Table 2.

Table 2.

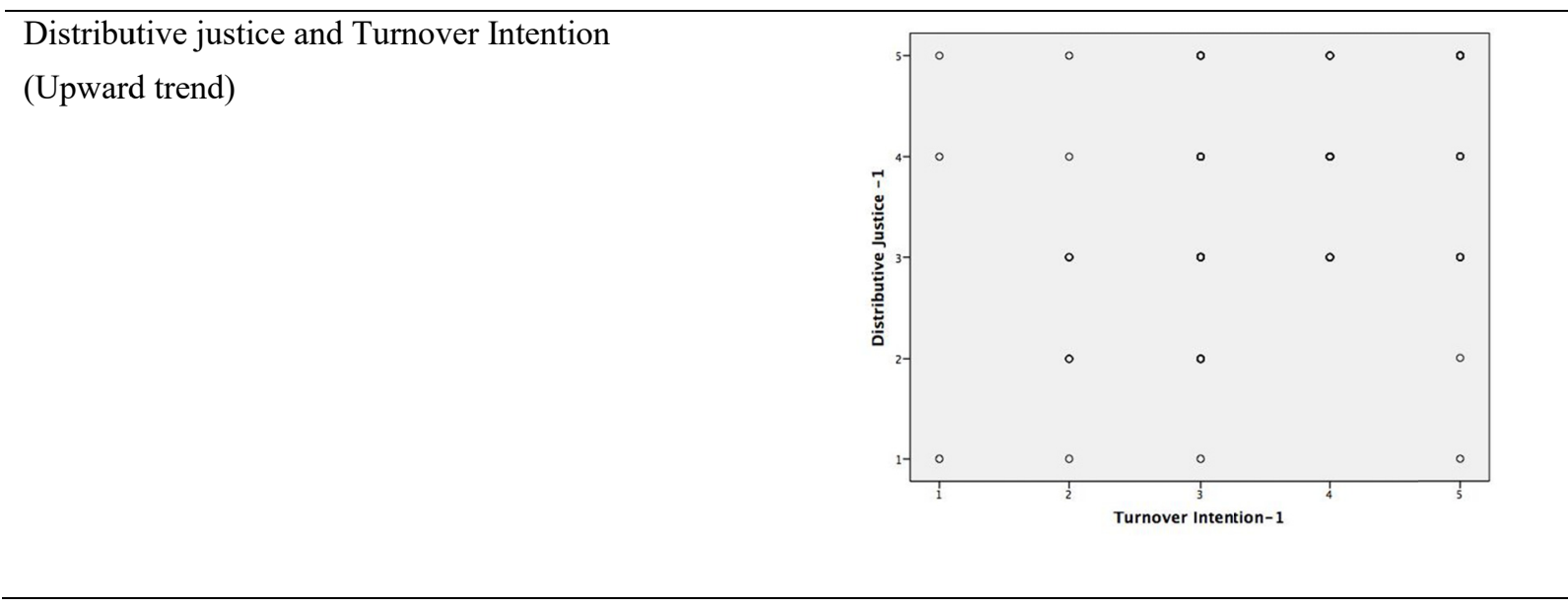




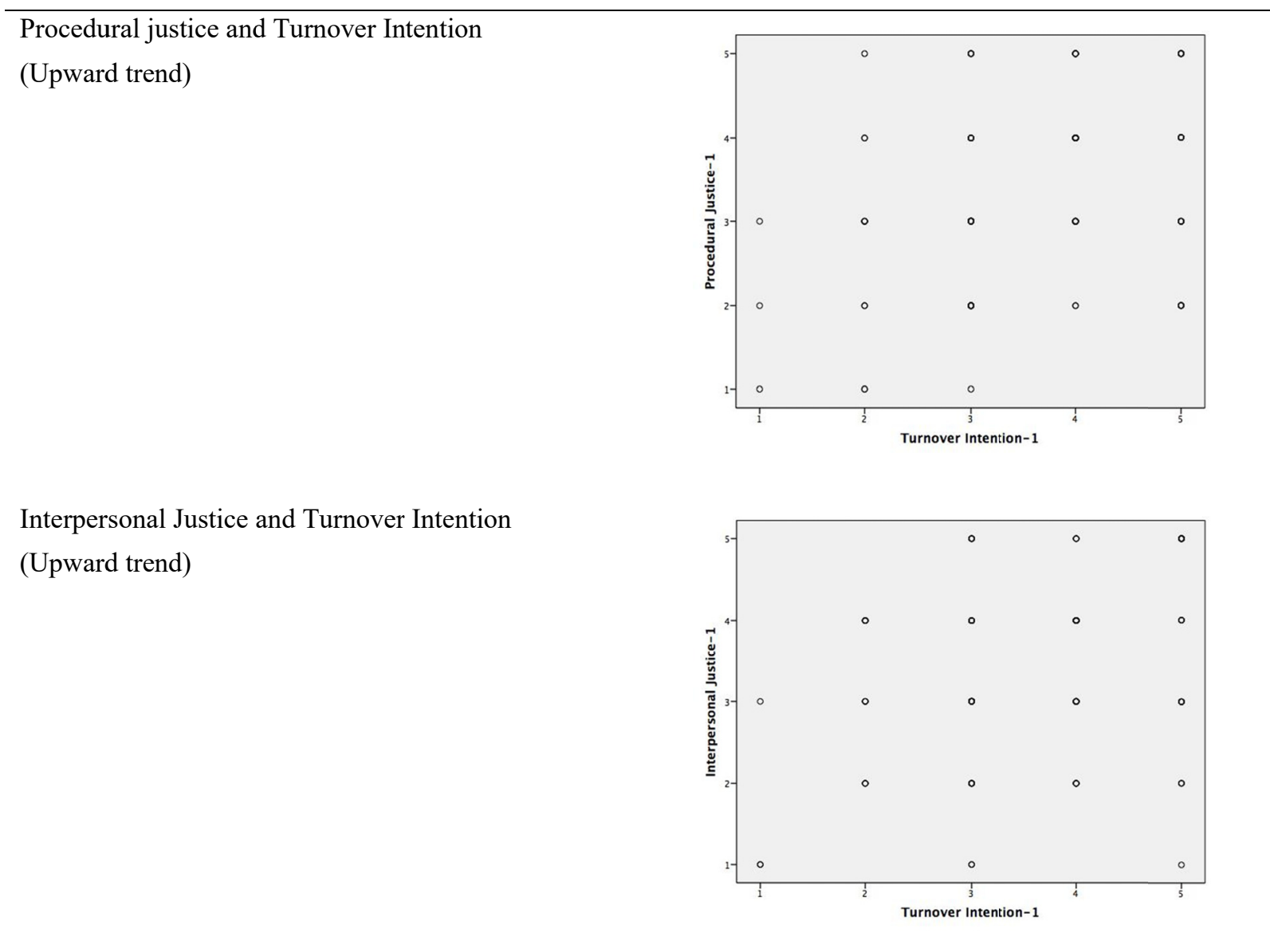

Table 3. Pearson's correlations for all variables

\begin{tabular}{lllll}
\hline Variable & Distribution justice & Procedural justice & Interpersonal Justice & Turnover intention \\
\hline Distribution Justice & 1 & 230 & 292 & 331 \\
Procedural Justice & 230 & 1 & 208 & 324 \\
Interpersonal Justice & 292 & 230 & 1 & 279 \\
Turnover Intention & 331 & 324 & 274 & 1 \\
\hline
\end{tabular}

In table 2 values, non-lower than 0.80 with no minus sign, for the three sets of variables are shown which, as discussed earlier, suggest solid, firm positive relation between the two variables in each set. Then, based on Cohen (as cited in Pallant 2005) who believes PR value readings between 0.5 and 1.0 suggests solid relation, hypotheses 1-3 suggested for the present study receive solid support through the analysis of the data collected through a questionnaire.

\subsection{Reliability Analysis}

Reliability is a scale instrument that provides the consistency of used instruments. With regard to this claim, authors need to test the variables reliability by conducting Cronbach's Alpha indicator. A Cronbach alpha above 0.7 considered significant. While the testing result of every item in this study indicates above 0.8 (Table 4.3 ) the internal consistency is appropriate.

Table 4. Reliability test

\begin{tabular}{|c|c|c|}
\hline Variable & Cronbach's Alpha Based on Standardized Items & Number of Items \\
\hline Distributive Justice & 0.825 & 5 \\
\hline Procedural Justice & 0.854 & 6 \\
\hline Interpersonal Justice & 0.860 & 7 \\
\hline Turnover Intention & 0.851 & 5 \\
\hline
\end{tabular}




\subsection{Hypotheses Testing}

\subsubsection{Correlation between Variables}

According to the data the estimate of linkage between the Turnover Intention and Distributive Justice is 0.175 with a Significance Value of 0.019 which indicates a week correlation between the Turnover Intention and Distributive Justice. Also, due to the founded data of 0.473 and a Significance Value of 0.000 which indicates a powerful link between the Turnover Intention and Procedural Justice. While a value of 0.242 with a significance value of 0.002 shows the link between the Turnover Intention and Interactional Justice is strong.

Table 5. Hypotheses testing

\begin{tabular}{lll}
\hline Variables & Correlation & Significance \\
\hline Distributive Justice & 0.175 & 0.019 \\
Procedural Justice & 0.324 & 0.000 \\
Interactional Justice & 0.242 & 0.002 \\
\hline
\end{tabular}

\subsubsection{Multiple Regressions}

The correlation between all the independent variables and the dependent variable is illustrated in the Multiple Regression table. If we refer to the Coefficient table, we can see that the independent variables which include, Interpersonal Justice and Distributive Justice displayed an impressive link with Turnover Intention; however Procedural Justice displayed no impressive links with Turnover Intention.

All the variables tested have a relationship of more than $50 \%$ except for interactional Justice which had 0.242 This signifies that the weak of the relationship was within the range of weak to strong among the variables tested for this research. Procedural Justice which is about 0.473 has the strongest relationship among all the variables indicating a very strong relationship.

Table 6. Multi Regression testing

\begin{tabular}{|c|c|c|c|c|c|c|c|c|c|c|}
\hline \multicolumn{11}{|l|}{ Coefficients } \\
\hline \multirow[t]{3}{*}{ Model } & \multirow{2}{*}{\multicolumn{2}{|c|}{$\begin{array}{l}\text { Unstandardized } \\
\text { Coefficients }\end{array}$}} & \multirow{3}{*}{$\begin{array}{l}\text { Standardized } \\
\text { Coefficients } \\
\text { Beta }\end{array}$} & \multirow[t]{3}{*}{$\mathrm{t}$} & \multirow[t]{3}{*}{ Sig. } & \multirow{2}{*}{\multicolumn{3}{|c|}{ Correlations }} & \multirow{2}{*}{\multicolumn{2}{|c|}{$\begin{array}{l}\text { Collinearity } \\
\text { Statistics }\end{array}$}} \\
\hline & & & & & & & & & & \\
\hline & $\mathrm{B}$ & Std. Error & & & & Zero-order & Partial & Part & Tolerance & VIF \\
\hline (Constant) & 1.451 & 0.377 & & 3.852 & 0.000 & & & & & \\
\hline Distributive Justice & 0.223 & 0.079 & 0.229 & 2.801 & 0.006 & 0.331 & 0.234 & 0.215 & 0.885 & 1.130 \\
\hline Procedural Justice & 0.235 & 0.079 & 0.238 & 2.980 & 0.003 & 0.324 & 0.248 & 0.229 & 0.925 & 1.081 \\
\hline Interpersonal Justice & 0.159 & 0.079 & 0.163 & 2.009 & 0.047 & 0.279 & 0.170 & 0.154 & 0.894 & 1.119 \\
\hline (Constant) & 2.038 & 0.437 & & 4.661 & 0.000 & & & & & \\
\hline Distributive Justice & .232 & 0.078 & 0.239 & 2.976 & 0.003 & 0.331 & 0.248 & 0.224 & 0.883 & 1.133 \\
\hline Procedural Justice & .224 & 0.078 & 0.226 & 2.883 & 0.005 & 0.324 & 0.241 & 0.217 & 0.922 & 1.084 \\
\hline Interpersonal Justice & 0.115 & 0.080 & 0.118 & 1.438 & 0.153 & 0.279 & 0.123 & 0.108 & 0.849 & 1.177 \\
\hline Age Range & -.297 & 0.118 & -0.195 & -2.512 & 0.013 & -0.252 & -0.211 & -0.189 & 0.942 & 1.062 \\
\hline \multicolumn{11}{|c|}{ Dependent Variable: Turnover Intention } \\
\hline
\end{tabular}

\subsection{Regression Analysis}

In table 4.4, the results of the multiple linear regression MLR analysis to examine the effect of three components of organizational justice as independent variables on Turnover Intention as the dependent one are illustrated. On an overall basis, the reading of 0.23 for the R Square value suggests that the 3D model can account for $23.3 \%$ of the different cases of Turnover Intention of the 140 participants which shows the fitness of the model used for the analysis, but the reduction of Adjusted R Square value to 0.21 the generalization of the model can still be enhanced. Furthermore, Procedural Justice is shown to have the most extensive impact (Beta $=0.436$ ) when forecasting Turnover Intention, while next in line is Distributive Justice (Beta $=0.022)$; the bottom determiner of Turnover Intention is Interpersonal Justice (Beta $=0.94)$. In all the three cases the degree of reliability is higher than $95 \%$ (p-value $<=0.05$ ). Just like the correlation analysis of the data, in the linear regression analysis also the three hypotheses proposed for the study all receive support for the influence of the three components of equity in the work place on Turnover Intention of the employees with implications that Procedural Justice as well as 
Distributive Justice are more important in enhancing the perceptions of individual's turnover intentions in the context of Malaysia.

Table 7. Linear Regressions among variables

\begin{tabular}{lllll}
\hline Variable & $\mathrm{R}$ & $\mathrm{R}$ Square & Adjusted R Square & Std. Error of the Estimate \\
\hline Distributive Justice & 0.331 & 0.110 & 0.103 & 0.962 \\
Procedural Justice & 0.347 & 0.120 & 0.114 & 0.900 \\
Interactional Justice & 0.392 & 0.154 & 0.147 & 0.883 \\
\hline
\end{tabular}

\subsection{Control Variables}

The control variables explored in the research had no significant effect or link to organizational justice and its impact on turnover intentions in tertiary institutions in Cyberjaya, Malaysia. This is in harmony with earlier research conducted by Salleh, M., (2009).

Gender/Sex, age, religion, level of education, marital status, race, specific field of academic achievements, duration of work in a company, and the level of management were all the control variables included in this study.

\section{Research Implications and Recommendation}

\subsection{Implications}

This research has beneficial implications for any organization as regards the way interactional, procedural and distributive justice can influence employee turnover intentions. It gives an insight to management of organizations on how to properly implement organizational justice so as to curb or reduce turnover intentions amongst employees.

Employee perception of fair treatment in relation to effective implementation of organizational justice can influence their turnover decisions. If employees perceive organizational justice as fair the tendency to entertain turnover intentions is minimal but if employees perceive the justice system in an organization as unfair, turnover intentions would be very high as there can be feelings of resentment, reduced loyalty and sense of belonging as well as thoughts of quitting finally.

In view of this, it is highly recommended that tertiary institutions in Cyberjaya, should consider their organizational justice practice and see if previous practice relates to the negative influence observed in this study and seek for strategic ways to improve it so as to discourage turnover intentions. Ensuring the effective practice of organizational justice would be beneficiary to tertiary institutions in Cyberjaya as they would be able to retain their employees and spend more time improving productivity rather than engaging in constant recruitment which could be detrimental to the work balance.

\subsection{Conclusion}

If we look at this research and all of its conclusions, the application of Organization Justice can have a powerful influence on an employee's Turnover Intention obviously and mainly when employees are in situations that they interpret it as bias. The gain of a personnel's understanding of equity in situations like an issuance of rewards can make other employees change with their behavioral purposes depending on their understanding of OJ which could be positive or negative.

The findings showed a relationship between the three justice characteristics studied (procedural, interactional, distributive) and their ability to impact on employees' turnover intentions. Hence it is pertinent for tertiary institutions in Cyberjaya to have a full understanding and grasp of the three justice characteristics so as to facilitate effective implementation and aid them to reduce the incidence of turnover intentions in amongst their employees. Tertiary institutions in Cyberjaya should therefore be concerned with ensuring proper organizational justice systems hinged on fairness, transparency and that would be consistent in supplying a proper amount of equity in different forms such as, systems for bonuses, care, interactional and formal systems. By considering these and ensuring proper implementation, there would be a reduction in the chances of employees leaving their jobs.

Finally, it is important to know that there might be other influences apart from these three justice characteristics mentioned in our study. Other organizational factors like politics in the organization or psychological contract violations might have a strong influence on employee turnover intentions. 


\subsection{Future Research}

The research was conducted in the area that still requires more attention. Therefore, further researches might be carried out by considering other factors like organizations' policies, Violation of Psychological contracts which also may affect personnel's turnover intention.

\section{References}

Al Rawashdeh, E. (2013). Organizational justice and its impact upon job performance in the Jordanian customs department. International Management Review, 9(2), 29-35. Retrieved 4 SEPT 2014.

Barrett, G. V., \& Kernan, M. C. (1987). Performance appraisal and terminations: A review of court decisions since Brito v. Zia with implications for personnel practices. Personnel Psychology, 40(3), 489-503. http://dx.doi.org/10.1111/j.1744-6570.1987.tb00611.x

BBC (2010). How Air Asia founder Tony Fernandes' dream came true. Retrieved from http://www.bbc.co.uk/news/business-11647205

Belanger, I. (2007). Models of the effects of monitoring on perceptions of organizational justice and turnover. (University of New Brunswick (Canada)). ProQuest Dissertations and Theses, Retrieved from http://search.proquest.com/docview/304730925?accountid=50207

Bluedorn A. C. (1982). A unified model of turnover from organizations. Human Relations, 35(2), 135-153 https://doi.org/10.1177/001872678203500204

Bowen, D. E., Gilliland, S. W., \& Folger, R. (1999). HRM and Service Fairness: how being fair with employees spills over to customers. Organizational Dynamics, 27(3), 7.

Burns, A. C., \& Bush, R. F. (2006). Marketing Research (5th Ed). New Jersey: Pearson Prentice Hall.

Choong, K.F., Wong, E.S.K. \& Tioh, N.G. (2010). The impact of organizational justice on employee's job satisfaction: The Malaysian companies perspectives. American Journal of Economics and Business Administration, 2(1),65-72.

Fodchuk, K. M. (2009). Organizational justice perceptions in china: Development of the Chinese organizational justice scale. (Order No. 3374154, Old Dominion University). ProQuest Dissertations and Theses, Retrieved from http://search.proquest.com/docview/305071073?accountid=50207

Gauri S. Rai (2013). Impact of organizational justice satisfaction, commitment and turnover intention: Can fair treatment by organizations make a difference in their workers' attitudes and behaviors?. International Journal of Human Sciences, 10(2), 260-284.

Georgalis, J., Samaratunge, R., Kimberley, N., \& Lu, Y. (2015). Change process characteristics and resistance to organisational change: The role of employee perceptions of justice. Australian Journal Of Management (Sage Publications Ltd., 40(1), 89-113. https://doi.org/10.1177/0312896214526212

Greenberg, J. (2010). Behavior in Organizations (10th ed.), England, Pearson.

Griffeth Rodger W., Hom, Peter W., \& Gaertner, S. (2000). A Meta-Analysis of antecedents and correlates of employee turnover: Update, moderator tests, and research implications for the next millennium. Journal of Management, 26(3), 463-488 https://doi.org/10.1177/014920630002600305

Guo, C. (2009). The meaning and effects of organizational justice in a layoff situation: An indigenous chinese investigation. (University of Massachusetts Amherst). ProQuest Dissertations and Theses, Retrieved from http://search.proquest.com/docview/304924039?accountid=50207.

Hamlett, J. (2014). Exploring how managers' perception of organizational justice influences job satisfaction and turnover intention. (Northcentral University), ProQuest Dissertations and Theses. Retrieved from http://search.proquest.com/docview/1548006654?accountid=50207.

Hellman, Chan M. (1997). Job satisfaction and intent to leave. The Journal of Social Psychology, 137(6), 677-689. https://doi.org/10.1080/00224549709595491

Hemdi, M. A., \& Nasurdin, A. M. (2006). Redacting turnover intentions of hotel employees: The influence of employee development human resource management practices and trust in organization. International Journal of Business, 8(1), 21-42.

Iyer, V. V. (2011). Understanding turnover intentions and behavior of indian information systems professionals: A study of organizational justice, job satisfaction and social norms. ProQuest Dissertations \& Theses Global. Retrieved from http://search.proquest.com/docview/915147174? accountid=5027 
Lambert, E. G., Lynne Hogan, N., \& Barton, S. M. (2001). The impact of job satisfaction on turnover intent: A Test of a Structural Measurement Model Using a National Sample of Workers. The Social Science Journal, 38, 233-250. http://dx.doi.org/10.1016/S0362-3319(01)00110-0

McNabb, N. S. (2009). The daily floggings will continue until morale improves: An examination of the relationships among organizational justice, job satisfaction, organizational commitment and intention to turnover. ProQuest Dissertations \& Theses Global. Retrieved from http://search.proquest.com/docview/304972141?accountid=5027

Moorman, R. H. (1991) Relationship between organizational justice and organizational citizenship behaviors: Do fairness perceptions influence employee citizenship? Journal of Applied Psychology, 76(6), 845-855.

Niehoff Brian P., \& Moorman Robert H. (1993) Justice as a Mediator of the Relationship Between Methods of Monitoring and Organizational Citizenship Behaviour. Academy of Management Journal, 36(3).

Oh, J. R. (2013). The impact of organizational justice on career satisfaction of employees in the public sector of South Korea. (University of Minnesota). ProQuest Dissertations and Theses. Retrieved from http://search.proquest.com/docview/1420349300?accountid=50207

Pallant, J. (2005). SPSS Survival Manual: A step by step guide to data analysis using SPSS for Windows (12th ed.), Australia, Allen \& Unwin.

Pekurinen, V. M., Välimäki, M., Virtanen, M., \& Salo, P., Kivimäki, M., \& Jussi, V. (2017) Organizational justice and collaboration among nurses as correlates of violent assaults by patients in psychiatric care. Psychiatric Services, 68(5) 490-496. https://doi.org/10.1176/appi.ps.201600171

Pyun, S. (1997). Organizational justice orientations and workforce performance effectiveness in south korea. (University of Southern California). ProQuest Dissertations and Theses, http://search.proquest.com/docview/304382623?accountid=50207. (304382623).

Robinson, K. L. (2004). The impact of individual differences on the relationship between employee perceptions of organizational justice and organizational outcome variables. ProQuest Dissertations \& Theses Global, Retrieved from http://search.proquest.com/docview/305047403?accountid=5027 Russell E. Johnson, Christopher Selenta, Robert G. Lord (2006). When organizational justice and the self-concept meet: Consequences for the organization and its members. Organizational Behavior and Human Decision Processes, 99(2), 175-201.

Salleh. R., Siti, R., Mohd S., Zulhan O., \& Mohd, J., (2009). An empirical assessment of hotel department managers' turnover intentions; the impact of organizational Justice. Emeralds journals, 4(8), 173-183.

Tam, W. W. (1998). An assessment of the relationships among organizational trust, organizational politics, and organizational justice, and their effects on merit pay outcomes in the Malaysian public sector. (The Pennsylvania State University). ProQuest Dissertations and Theses. Retrieved from http://search.proquest.com/docview/304443454?accountid=50207. (304443454).

Tett, P., \& Meyer, J. P. (1993). JOB satisfaction, organizational commitment, turnover intention, and turnover: Path analysis based on Meta-Analytic findings. Personnel psychology, 46(2) 259-293.

Vineet, N. (2010). Employee first, customer second: Turning conventional management upside down. Harvard Business School Publishing, United State.

Wan, H., Sulaiman, M., \& Omar, A. (2012). Procedural justice in promotion decisions of managerial staff in Malaysia. Asia Pacific Business Review, 18(1), 99-121. https://doi.org/10.1080/13602380903424167

Zhang, H. (2006). Antecedents and consequences of organizational justice: An investigation in china. (McMaster University (Canada)). ProQuest Dissertations and Theses, Retrieved from http://search.proquest.com/docview/305274556?accountid=50207

\section{Copyrights}

Copyright for this article is retained by the author(s), with first publication rights granted to the journal.

This is an open-access article distributed under the terms and conditions of the Creative Commons Attribution license (http://creativecommons.org/licenses/by/4.0/). 